Original Research Article

\title{
A clinical study of prevalence of ocular manifestations in malnourished children attending Anganwadi centers in urban slum areas
}

\author{
Singh $\mathbf{P}^{1}$, Kumar $\mathbf{R}^{2}$, Das $\mathbf{S}^{3}$ \\ ${ }^{1}$ Dr. Priti Singh, Assistant Professor, Department of Ophthalmology, GMC, Bhopal, MP, ${ }^{2}$ Dr. Rashmi Kumar, \\ Assistant Professor, Department of Ophthalmology, L. N. Medical College, Bhopal, ${ }^{3}$ Dr. Swarna Das, Post \\ Graduate Student, Department of Pathology, S.S.M.C, Rewa, MP, India.
}

Address for Correspondence: Dr Rashmi Kumar. E-mail: rashmikumardr@gmail.com.

\begin{abstract}
Aim: A clinical study of prevalence of ocular manifestations in malnourished children attending anganwadi centers in urban slum areas. Material \& Method: A cross sectional study was carried out in Anganwadi centers of urban slum area, with children of age group $0-6$ years. All children underwent detailed systemic and ocular examination and were graded for malnutrition according to IAP classification. The results were analysed statistically. Results: In our study the prevalence of ocular manifestations is 9.6\% (50). Prevalence of malnutrition is $18.53 \%$ (96). Out of 96 malnourished, 56 children $(58.33 \%)$ belong to grade I malnutrition, out of which 16 children (32\%) had ocular manifestation, which is total ocular manifestation in all the grades of malnutrition. So, ocular manifestation in malnourished children is $32 \%$. Overall ocular involvement was seen in 50 children out of 518 children examined, with overall prevalence of $9.65 \%$. Thereis significant difference of ocular involvement between malnourished and wellnourished ( $p$ value - 0.017). Conclusion: Overall prevalence of malnourished children wasfound to be very less at anganwadi centers in our study. This may be probably due to the timely vaccination of children and the nutritional supplements being provided to them at Anganwadi centers through various national programmes.
\end{abstract}

Key words: Malnutrition, Xerophthalmia, Keratomalacia, Bitot'sspot.

\section{Introduction}

Ocular involvement in malnourished children is quite frequent. The effects of malnutrition on eye are frequently more serious during the formative years of life. This is an important cause of preventable blindness and is to be taken care of through cost effective means. Prevention of xerophthalmia is of utmost value in preventing childhood blindness.

Vitamin A deficiency is the most important cause of preventable blindness inyoung children. It has been a nutritional problem ofpublic health significance in India and continues to be so even though the National Vitamin A Prophylaxis Programme has been inoperation for more than

Manuscript received: $28^{\text {th }}$ October 2017

Reviewed: $6^{\text {th }}$ November 2017

Author Corrected: $14^{\text {th }}$ November 2017

Accepted for Publication: $21^{\text {st }}$ November 2017 three decades [1]. Vitamin A deficiency (VAD) has been recognized as a major preventable public health and nutritional problem in India. An estimated $5.39 \%$ children in India suffer from eye signs of VAD. The prevalence was higher than WHO cut off level of $0.5 \%$, indicating the public health significance of the problem of VAD [1].

VAD is identified as the most common single cause of childhood blindness with measles as an important precipitating factor [2]. The formulation of an effective intervention health programme begins with the knowledge of the magnitude of the problem in a given community. Although costly and time consuming the actual assessment of a health problem is far less expensive than the intervention itself and may suggest where and how prevention activities can best be implemented. 
Original Research Article

The need of this study is to know the nature, magnitude and severity of ocular manifestations in malnourished children and to assess the present situation of prevalence of this more so in the urban slum area, in view of improving parameters of nutrition, by increasing awareness, education and information of vaccination and nutrition,by Anganwadi workers.

A study pattern of ocular manifestations in children is very important because, while some conditions such as refractive errors and cataract are treatable others like measles and vitamin A deficiency are largely preventable.

Many ocular diseases have their origin in childhood and the morbidity may go unnoticed and cause severe ocular disability in the later part of life.

Effective methods of vision screening and ocular manifestations in toddlers and young children are useful in detecting correctable causes of decreased vision and in minimizing long term visual disability. Considering the fact that $30 \%$ of India's blind lose their sight before age of 20 years, the importance of early detection and treatment of ocular morbidity and visual impairment in young children is obvious [3].

India is a developing country, hence prone more to malnutrition, such as vitamin A deficiency. Our Indian Government is stressing more and more on malnourishment and so many programs and strategies are made and being implemented over the grass root level.

The present study was conducted in Anganwadi centers in urban slum area with the objective of estimating prevalence of ocular manifestations in malnourished children as Anganwadi centers are at present most targeted and benefited from Indian government schemes and programmes.

By looking at these facts, the present study is undertaken to find out the prevalence of ocular manifestations associated with nutritional deficiencies in the relatively more vulnerable group of children with the hope, that it would provide useful information regarding magnitude of the problem and would also lead to a better understanding of related factors, enabling us to tackle it more effectively.

\section{Objectives}

To identify malnourished children in Anganwadi centers in urban slum areas

1. To assess the prevalence of ocular manifestations in those malnourished children.

2. To assess the severity of ocular manifestation in respect with the grades of malnutrition.

3. To assess the prevalence of childhood blindness in these children due to ocular complications.

\section{Material and Method}

This study was carried out in department of Ophthalmology, L.N. Medical College from July 2014 to October 2014 in this study, eye camps were conducted in nearby urban slum anganwadicenters of Kolar area. We included 518 children coming in those Anganwadi centers of age group 0-6 years.

\section{Inclusion criteria}

- All children of 0-6 year age group attending urban slum anganwadicentres of Kolar area.

\section{Exclusion criteria}

- Children more than 6 years in age.

- Children who are not registered in those centres.

- Children with history of ocular trauma or any other pre-existing ocular disease were excluded.

The diagnosis was established on clinical findings. Children were identified in terms of name, age, sex and address and were assigned a serial number. A detailed history was elicited from the parents or from the patient himself wherever possible and was written down on a predesigned format. The ocular and general complaints with duration were noted. The history of present illness was enquired in detail including the mode of onset of symptoms with duration from mother/care taker.A detailed history of diet and dietary habits of each patient was noted. A past history of general and ocular illness was noted to know whether the patient was chronologically ill and/ or suffered from any eye disease of significance.

Detailed family history including occupation of parents, per capita income of the family, educational status of parents, number of siblings and any similar complaint in any of them. The examination of the patient was conducted under the following headings: 
1. General Examination: Age, height, weight of the child, skin/hair changes, pitting edema over extremities.

2. Grading of malnutrition: We have used the Indian Academy of Pediatrics (IAP) classification for grading of malnutrition [4].

IAP classification for malnutrition[4]

Grade of malnutrition Weight for age of the standard (median) $\%$

Normal $>80 \%$

Grade $171-80 \%$ (mild malnutrition)

Grade $261-70 \%$ (moderate malnutrition)

Grade $351-70 \%$ (severe malnutrition)

Grade $4<50 \%$ (very severe malnutrition)

3. Systemic examination: All the systems were examined with emphasis on GIT and respiratory tract infection.

4. Ocular Examination: Detailed Ocular examination was conducted using torch light and binocular loupe in the anganwadicentres itself.

5. Vision

- Recording of visual acuity in infants and younger age group children was not possible.

- It was recorded by Snellen's chart in school going children and also by picture chart in the children who were unable to read the alphabets.
Original Research Article

Fundus Examination: It was done wherever possible. If the child was irritable, oral sedation was given. Results were calculated out of total 518 children examined in various Anganwadi centres taking into consideration following ocular problems -

1. Xerophthalmia-

- Night blindness

- Conjunctivalxerosis

- Bitot's spots

- Corneal xerosis

- Corneal ulcer/Keratomalacia

- Corneal scar

- Xerophthalmic fundus

2. Blepharitis

3. Allergic Conjunctivitis

4. Phlyctenular conjunctivitis

5. Stye

6. Others like Trachoma etc.

The data was then analysed statistically and chi square test was applied. Permission for study was taken from institutional ethics committee (IEC) prior to commencement of study.

\section{Results}

Out of 518 children examined, 96 children were malnourished with a prevalence of $18.53 \%$ and 50 children had ocular findings with a prevalence of $9.6 \%$. In this study $40(7.7 \%)$ had xerophthalmia, Bitot's spot in $6(1.15 \%)$ and Conjunctival Xerosis in 34 (6.56\%) of children.

Table-1: Ocular findings in malnourished children.

\begin{tabular}{|c|c|c|c|}
\hline S.No & Finding & No. of children found & Prevalence \\
\hline 1. & Bitot's Spot & 06 & $1.15 \%$ \\
\hline 2. & ConjunctivalXerosis & 34 & $6.56 \%$ \\
\hline 3. & Blepharitis & 04 & $0.77 \%$ \\
\hline 4. & Allergic Conjunctivitis & 08 & $1.54 \%$ \\
\hline 5. & Stye & 06 & $1.15 \%$ \\
\hline
\end{tabular}

As per the table Conjunctival xerosis was most common finding observed.

Table-2: Additional ocular findings in malnourished children

\begin{tabular}{|c|c|c|c|}
\hline S.No & Additional Ocular Findings & No. of Children & Prevalence \\
\hline 1. & Pigmentations of Conjunctiva & 22 & $4.24 \%$ \\
\hline 2. & Watering & 6 & $1.15 \%$ \\
\hline 3. & Heterochromiairidis & 4 & $0.77 \%$ \\
\hline
\end{tabular}

It was not possible to do dark adaptation test at anganwadicentres, so we enquired about the history of night blindness from the mothers. To our surprise not even a single mother gave the history of night blindness. This may be due to lack of awareness due to illiteracy. 
Original Research Article

Table-3: Gender wise distribution of ocular manifestations in all children examined

\begin{tabular}{|c|c|c|c|c|}
\hline \multirow{2}{*}{$\begin{array}{c}\text { Total number of } \\
\text { well nourished } \\
\text { children (422) }\end{array}$} & \multicolumn{2}{|c|}{ Girls (230) } & \multicolumn{2}{c|}{ Boys (192) } \\
\cline { 2 - 5 } & $\begin{array}{c}\text { With ocular } \\
\text { involvement }\end{array}$ & $\begin{array}{c}\text { Without ocular } \\
\text { involvement }\end{array}$ & $\begin{array}{c}\text { With ocular } \\
\text { involvement }\end{array}$ & $\begin{array}{c}\text { Without ocular } \\
\text { involvement }\end{array}$ \\
\cline { 2 - 5 } & 20 & 210 & 14 & 178 \\
\hline Prevalence & $8.6 \%$ & $90.51 \%$ & $7.29 \%$ & $92.7 \%$ \\
\hline
\end{tabular}

Girls were more commonly affected than boys.

Table-4 - Gender wise distribution of ocular manifestations in all malnourished children.

\begin{tabular}{|c|c|c|c|c|}
\hline \multirow{2}{*}{$\begin{array}{c}\text { Total number of } \\
\text { malnourished } \\
\text { children (96) }\end{array}$} & \multicolumn{2}{|c|}{ Girls (46) } & \multicolumn{2}{c|}{ Boys (50) } \\
\cline { 2 - 5 } & $\begin{array}{c}\text { With ocular } \\
\text { involvement }\end{array}$ & $\begin{array}{c}\text { Without ocular } \\
\text { involvement }\end{array}$ & $\begin{array}{c}\text { With ocular } \\
\text { involvement }\end{array}$ & $\begin{array}{c}\text { Without ocular } \\
\text { involvement }\end{array}$ \\
\cline { 2 - 5 } & 6 & 40 & 10 & 40 \\
\hline Prevalence & $13.04 \%$ & $86.95 \%$ & $20 \%$ & $80 \%$ \\
\hline
\end{tabular}

Table-5: Prevalence of ocular manifestations in malnourished children.

\begin{tabular}{|c|c|c|c|c|}
\hline $\begin{array}{c}\text { Total } \\
\text { malnourished }\end{array}$ & $\begin{array}{c}\text { With ocular } \\
\text { involvement }\end{array}$ & Prevalence & $\begin{array}{c}\text { Without ocular } \\
\text { involvement }\end{array}$ & Prevalence \\
\hline 96 & 16 & $16.6 \%$ & 80 & $83.3 \%$ \\
\hline
\end{tabular}

Table 6- Grades of malnutrition and relation with prevalence of ocular involvement.

\begin{tabular}{|c|c|c|c|c|}
\hline $\begin{array}{c}\text { Grades of } \\
\text { malnutrition }\end{array}$ & $\begin{array}{c}\text { Malnourished } \\
\text { children }\end{array}$ & Prevalence & $\begin{array}{c}\text { Ocular } \\
\text { involvement }\end{array}$ & Prevalence \\
\hline & No. & $\%$ & No. & $\%$ (out of 50) \\
\hline Grade I & 56 & 58.33 & 16 & 32 \\
\hline Grade II & 30 & 31.25 & & \\
\hline Grade III & 6 & 6.25 & & \\
\hline Grade IV & 4 & 4.166 & & \\
\hline Total & $\mathbf{9 6}$ & & & \\
\hline
\end{tabular}

Table-7: Overall result

\begin{tabular}{|c|c|c|c|c|}
\hline Total & \multicolumn{2}{|c|}{ Malnourished (96) } & \multicolumn{2}{c|}{ Well nourished (422) } \\
\hline & $\begin{array}{c}\text { With ocular } \\
\text { involvement }\end{array}$ & $\begin{array}{c}\text { Without ocular } \\
\text { involvement }\end{array}$ & $\begin{array}{c}\text { With ocular } \\
\text { involvement }\end{array}$ & $\begin{array}{c}\text { Without ocular } \\
\text { involvement }\end{array}$ \\
\hline 518 & $16(16.6 \%)$ & $80(83.35 \%)$ & $34(8.05 \%)$ & 388 \\
\hline
\end{tabular}

Significance of difference between two proportions- Ocular involvement difference between malnourished and well nourished were seen. $X^{2}=5.697$ with degree of freedom 1.P value $=0.017$, So, it shows that there is asignificant difference of ocular involvement between malnourished and well nourished.

\section{Discussion}

The present study was undertaken in the light of the available literature to determine the prevalence of ocular manifestations in malnourished children and to evaluate the efficacy of preventive public health measures in combating childhood blindness. In this study, a series of 518 children were examined. Prevalence of ocular involvement in our observation of 518 children, $50(9.6 \%)$ had ocular involvement out of which 40(7.7\%) had xerophthalmia, Bitot's spot- $6(1.15 \%)$ and Conjunctival Xerosis- 34 (6.56\%). Dole K et al (2009) worked on prevalence and determinants of xerophthalmia in preschool children in urban slums in Pune and found xeropthalmia in $1.32 \%$ cases [5]. Gupta Y et al ( 2011) done a similar study in rural population in UP, India, and found prevalence of 
Bitot's spots $0.90 \%$ [6]. In our study prevalence of bitot's spot is $1.15 \%$ which is more than that found in school eye survey as our study was done in urban slum areas with predominantly lower socioeconomic background children. Arlappa N et al (2011) have done a study on Prevalence of vitamin A deficiency and its determinants among rural preschool children of MP, India with results that prevalence of night blindness and bitot's spots was $0.8 \%$ \& $1.4 \%$ respectively and prevalence increased significantly with age $(\mathrm{P}<0.001)$ and more in low socioeconomic and illiterate mother [1].

Laxmaiah A et al (2012) in their study of rural preschool children found $0.8 \%$ prevalenceof bitot's spot [7]. Duke university eye centre study found the Prevalence of xerophthalmia (20.8\%) among malnourished children in rural Ethiopia [8].

The high prevalencemay be due to the fact that it is a very under developed African country. In another study, Vitamin A deficiency was found in. 278 children $(5.39 \%)$. The highest prevalence occurred in the age group of 4 to 6 years and in families with income less than Rs.500/= per month $(10.2 \%)$ and in Muslims (8.7\%) [3].

Out of 50 children having ocular involvement, boys were 24 out of 242 total boys $(9.91 \%)$ and girls were 26 out of 276 total girls $(9.42 \%)$. Ocular involvement is almost equal. Dole $\mathrm{K}$ et al observed nogender difference [2]. In our study, sex prevalence difference is almost equal.

Laxmaiah A et al found total ocular signs were significantly higher $(\mathrm{P}<0.001)$ among boys $(2-6 \%)$ compared with girls (1-9\%) [7]. In our study boys $\&$ girls have equal prevalence. (Girls with prevalence of $9.42 \%$ and Boys with prevalence of $9.91 \%)$.

We found in our study that the maximum number of malnourished children were 96 (18.53\%). As well in those malnourished children, only $16(32 \%)$ were having ocular involvement out of 50 children with ocular involvement. Rest 34 (68\%) children were not malnourished, means were normal, but still showed ocular involvement. Also all these 16 children belongs to Grade I only. So, we had negative association with grades of malnourishment.
Gopaldas et al (1993) found that there was a negative association between the prevalence of xerophthalmia and the degree of malnutrition. 65 children in the normal and grade I, 5\% in grade II, $3 \%$ in grade III and $2 \%$ in grade IV exhibited eye signs [9].

Duke university eye centre study observed that Severely malnourished were more likely to suffer from xerophthalmia than moderately and mild malnourished $(\mathrm{p}<0.0001)$.

Xerophthalmia is common global cause of pediatric blindness and is highly correlated with severe malnutrition [8]. No correlation with severe or increase of grades of malnourishment was found in our study. All malnourished children with ocular involvement were in grade I only.

It was observed that there is a significant difference of ocular involvement between malnourished and well nourished.

In a similar type of study done in Nepal in 1998, they also found a drastic reduction in incidence of bitot's spot and night blindness among preschool children in last 21 years because of the national programmes like national vitamin A programme (NVAD) [10].

It shows that facilities provided in urban slum Anganwadi centers are up to the expectations of strategies and schemes being started by Indian government. Increased vitamin A supplementation, health and nutrition education and consumption of vitamin A rich foods are essential to prevent vitamin A deficiency ( VAD ) [11].

\section{Conclusion}

The present study was aimed at evaluating the prevalence of ocular manifestations in malnourished children attending urban anganwadi centres. Pre-school children form an important target group which must be screenedadequately for early detection of eye diseases and prevention of VAD. Also, every child should be immunized and given prophylaxis for vitamin A.

Our study revealed that VAD is a major nutritional problem and coverage of vitamin A supplementation needs improvement. The important factors for $\mathrm{VAD}$ were found to be low socioeconomic 
status, illiterate parents and poor sanitation. Vitamin A supplementation programme should be strengthened through anganwadi centres and this will go a long way in preventing childhood blindness and morbidity. It is also equally important to educate mothers about sanitation, nutritionand immunization.

\section{Funding: Nil, Conflict of interest: None Permission of IRB: Yes}

\section{Reference}

1. Arlappa N, Balakrishna N, Laxmaiah A, Raghu P, Rao VV, Nair KM, Brahmam GN. Prevalence of vitamin A deficiency and its determinants among the rural pre-school children of Madhya Pradesh, India. Ann Hum Biol. 2011 Mar;38(2):131-6. doi: 10. 3109/ 03014460. 2010. 498794. Epub 2010 Jul 15.

2. Rahi JS, Sripathi S, Gilbert CE, Foster A. Childhood blindness in India: causes in 1318 blind school students in nine states. Eye (Lond). 1995;9 (Pt 5): 545-50.

3. Desai S, Desai R, Desai NC, Lohiya S, Bhargava G, Kumar K. School eye health appraisal. Indian J Ophthalmology. 1989; Vol 37: Issue 4; pages 173-175.

4. Paul VK, Bagga A, editors. GHAI Essential Paediatrics. $8^{\text {th }}$ edition.Delhi:CBS Publishers, 2013. Table no.6.7,IAP classification of malnutrition;p97.

5. Dole K, Gilbert C, Deshpande M, Khandekar R. Prevalence and Determinants of Xerophthalmia in Pre School Children in Urban Slums, Pune, India- A Preliminary Assessment. Journal Ophthalmic Epidemiology, Vol 16, 2009-issue 1; 8-14.
6. Gupta Y, Sukul RR, Gupta M, Phougat A, Jain R, Varshney A. School eye survey in rural population in UP, India. Nepal J Ophthalmol. 2011 Jan-Jun;3(1):78-9. doi: 10.3126/nepjoph.v3i1.4282.

7. Laxmaiah A, Nair MK, Arlappa N, Raghu P, Balakrishna N, Rao KM, Galreddy C, Kumar S, Ravindranath M, Rao VV, Brahmam GN. Prevalence of ocular signs and subclinical vitamin A deficiency and its determinants among rural preschool children in India. Public Health Nutr. 2012 Apr;15(4):568-77.doi: 10.1017/S13689800110021 4X. Epub 2011 Sep 2.

8. Moore DB, Shirefaw W, Tomkins-Netzer O, Eshete Z, Netzer-Tomkins H, Ben-Zion I. Prevalence of xerophthalmia among malnourished children in rural Ethiopia. IntOphthalmol. 2013 Oct;33(5):455-9. doi: 10.1007/s10792-013-9715-9. Epub 2013 Jan 25.

9. Gopaldas T, Gujral S, Abbi R. Prevalence of xerophthalmia and efficacy of vitamin A prophylaxis in preventing xerophthalmia coexisting with malnutrition in rural Indian children. J Trop Pediatr. 1993 Aug;39(4):205-8.

10. Gorstein J, Shreshtra RK, Pandey S, Adhikari RK, Pradhan A. Current statusof vitamin A deficiency and the NationalVitamin A Control Program in Nepal: results of the 1998 National Micronutrient Status Survey. AsiaPac JClinNutr. 2003; 12 (1):96-103.

11. Arlappa N, Laxmaiah A, Balakrishna N, Harikumar R, BrahmamGN.Clinical and subclinical vitamin A deficiency among rural preschool children of Maharashtra, India. Ann Hum Biol. 2008 Nov-Dec;35(6):606-14. doi: 10.1080/ 03014460802380778.

\section{How to cite this article?}

Singh P, Kumar R, Das S. A clinical study of prevalence of ocular manifestations in malnourished children attending Anganwadi centers in urban slum areas. Int J Med Res Rev 2017;5(11):956-961.doi:10.17511/ijmrr. 2017.i11.07 